\title{
DESENVOLVIMENTO DE UM APRENDIZADO HÍBRIDO NO ENSINO DE FÍSICA EM CURSOS DE ENGENHARIA
}

\author{
Larissa Maciel do Nascimento ${ }^{1}$ \\ Elisangela Pavanelo² \\ José Silvério Edmundo Germano ${ }^{3}$
}

Resumo: $O$ ensino de física necessita de novas estratégias tanto no ambiente da sala de aula quanto nos baseados na internet, já que o público alvo que chega às escolas em todos os níveis vem com outras demandas e está sujeito a todo tempo e lugar a esse bombardeio de inovações que surgem a cada dia. É necessário portanto, testar, validar novas metodologias e reorganizar conteúdos, bem como qualificar todos os "atores" que hoje trabalham no ensino e se preocupam com o processo de ensino e aprendizagem. Neste sentido, esse trabalho apresenta um estudo da aplicação da metodologia denominada Aprendizado Hibrido (Blended Learning).

Palavras-chave: Ensino a distância; Instrução assistida por computador; Física.

\footnotetext{
1 Instituto Tecnológico de Aeronáutica, Brasil. E-mail: chazfisica@gmail.com.

2 Instituto Tecnológico de Aeronáutica, Brasil. E-mail: elisangela.pavanelo@gmail.com.

3 Instituto Tecnológico de Aeronáutica, Brasil. E-mail: silverio@ita.br.
} 